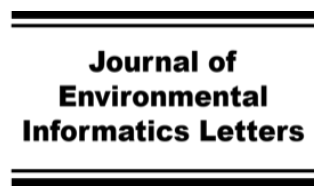

www.iseis.org/jeil

\title{
A Review of Response Options to Accelerate the Recovery of Oiled Shorelines
}

\author{
E. Owens ${ }^{1}{ }^{*}$, E. Taylor ${ }^{2}$, G. Sergy ${ }^{3}$, C. J. An ${ }^{4}$, Z. Chen ${ }^{4}$, and K. Lee ${ }^{5}$ \\ ${ }^{1}$ Owens Coastal Consultants Ltd., 755 Winslow Way East \# 205, Bainbridge Island, WA 98110, USA \\ ${ }^{2}$ Polaris Applied Sciences Inc., Bainbridge Island, WA 98110, USA \\ ${ }^{3}$ S3 Environmental, Edmonton, AB T6J 7G3, Canada \\ ${ }^{4}$ Department of Building, Civil and Environmental Engineering, Concordia University, Montreal, QC H3G 1M8, Canada \\ ${ }^{5}$ Fisheries and Oceans Canada, Ottawa, ON K1A OE6, Canada
}

Received 17 December 2020; revised 26 January 2021; accepted 26 February 2021; published online 04 April 2021

\begin{abstract}
The rate at which oil on shorelines weathers and attenuates is a function of the character of the oil on the shoreline (type and volume), the character of the shoreline materials, and the environmental setting (physical and biological). Some light crude oils or products have a very short half-life and may persist for only hours or days whereas other oils may persist for months to years. The objective of this review is to summarize how and why the different commonly used and available response options can contribute to accelerating shoreline recovery and to explain the potential consequences of these actions. Globally, the most widely used shoreline treatment activity is simple physical removal by manual or mechanical cleanup methods with off-site disposal. The explanation for this situation lies in the fact that this method is typically quick, easy, and requires no special skill sets or dedicated equipment. The second most widely used treatment method is low-pressure flushing or washing. A concern with this option is that typically little or no oil is recovered, unless the oil loading on the shore is very high and, although some of the oil may be broken down and dispersed in the water column and then biodegraded, if the method generates oil residue-sediment aggregates these may be negatively buoyant when the sediments are granular (> $1 \mathrm{~mm}$ ) or coarser. Many guides and manuals describe the mechanics and implementation of these and other treatment methods; this review evaluates the state-of-the art with respect to currently available and widely applicable treatment options to accelerate oiled shoreline recovery. This knowledge is intended to support the creation of a science-based Shoreline Response Program (SRP) Decision Support Tool that is under development as part the Fisheries and Oceans Canada Multi-Partner Research Initiative (MPRI) program. The primary benefit of this tool is to enhance the quality of strategic planning regarding shoreline response intervention and non-intervention decisions related, in part, to Alternative Response Technologies for shoreline treatment.
\end{abstract}

Keywords: oiled shorelines, shoreline cleanup, remediation, decision-making, treatment options

\section{Introduction}

The ecological recovery of shorelines impacted by spilled oil depends to a large extent on the sensitivity and vulnerability of the organisms affected by the oil, the type and volume of the oil, and the oil persistence. Recovery in the broader sense also involves the return of many cultural, economic and other human uses of the shore zone and the adjacent backshore to prespill activity levels. Understanding the persistence of stranded oil and the nature and duration of the exposure time for organisms and human activities affected by the oil is the first step in the development of a response action plan. This topic is addressed by two companion papers in this Special Issue (Owens et al., 2021a; Taylor, et al., 2021). If the estimated persistence of oil and the anticipated impact and recovery time scale is not acceptable then a response operation can be developed that may involve a range of physical, biological and chemical intervene-

${ }^{*}$ Corresponding author. Tel.: +12063693679

E-mail address: ed@owenscoastal.com (E. Owens).

ISSN: 2663-6859 print/2663-6867 online

(C) 2021 ISEIS All rights reserved. 10.3808/jeil.202100049 tion options to reduce that time scale. This decision process involves understanding the stranded oil transformation processes (weathering) and translocation pathways (transport) and is an essential foundation to the development of scientifically defensible and ecologically sound decisions regarding shoreline treatment to accelerate recovery. Importantly, some of these pathways may involve interactive biological, chemical and physical processes that may require explanation in a manner that is understandable by the full range of disciplinary practitioners as well as non-technical users who would need to understand the persistence and fate of oil stranded on shorelines. This topic is addressed by a companion discussion that presents a simple conceptual model that is science-based and yet readily understandable by decision-makers, planners and others not directly familiar with stranded oil weathering processes and attenuation pathways (Owens et al., 2021a).

Response planning relies, to a greater or lesser degree, on modeling predictions or estimates of the behavior of spilled oil for specific scenarios based on oil type, volumes, and the environmental setting (Taylor et al., 2021). These scenarios form a key component of the Shoreline Response Program (SRP) Decision Support Tool which is under development as part the 
Fisheries and Oceans Canada Multi-Partner Research Initiative (MPRI) program (Owens et al., 2021b).

\section{The Decision Process in a Shoreline Response Program}

There are many aspects to a shoreline response program including decisions regarding shoreline treatment objectives, priorities, treatment or cleanup options, operational constraints (Good Management Practices: GMPs), and treatment criteria (or endpoints) (IPIECA-IOGP, 2020; Owens and Santner, 2021). The decisions on whether to let Nature take its course or to intervene to remove the oil and/or accelerate the weathering and attenuation processes depend on understanding the processes that act on the stranded oil and the rates by which oil is transformed into non-hydrocarbon materials and/or non-degradable residue. If the decision is made that natural attenuation is not an acceptable strategy, then treatment options are reviewed for operationally viable and practical techniques that meet the treatment objectives. An evaluation of the potential consequences of proposed actions and their alternatives may be undertaken by a Net Environmental Benefit Analysis (NEBA) (Baker et al., 1993; IPIECA-IOPG, 2015) or a Spill Impact Mitigation Analysis (SIMA) (IPIECA-IOPG, 2018). In the majority of cases these treatment or cleanup operations targets are selected to ensure that response activities do not cause greater effects than the presence of the oil. This evaluation must include the identification of the treatment criteria and targets, historically referred to as "treatment end points", so that the operations and management teams can identify when sufficient treatment has been completed.

\subsection{Shoreline Treatment Criteria}

Treatment criteria represent the agreed upon, practical definition of 'acceptably clean' at a particular point in time. They provide targets for response operations and a benchmark to make an assessment on the status of shoreline cleanup for each defined site or segment of coast. Good practice involves establishing the treatment criteria process as part of the planned response phase but also includes setting interim criteria in the emergency response phase to temporarily guide the initial field operations (Owens and Santner, 2021). Treatment criteria may be phased, using feedback from real-time response results.

Typically, during the first stage of a shoreline response the objective is to recover bulk oil concentrations or mobile oil before it is reworked, buried or remobilized through natural processes. This strategy involves a set of initial interim treatment targets that may leave some of the stranded oil for a later phase of cleanup or for natural attenuation. This type of long-term strategy for a shoreline response program is a phased approach to achieve the treatment completion criteria. Managers and stakeholder representatives involved in the development of criteria that define treatment completion may be reluctant to finalize these completion criteria at the beginning of a response, particularly if the proposed criteria involve leaving some residual oil for natural attenuation. In addition, there may be a desire to review, and possibly revise, criteria part-way through a response. The strategy of phased treatment criteria rather than the development of "final" treatment targets at the outset addresses this issue. This flexible approach was used on the Deepwater Horizon Shoreline Response Program during which No Further Treatment (NFT) criteria required at the time were developed for different phases of the response ("2010 NFT", "2011 NFT", etc.) (Santner et al., 2011). A phased approach provides an opportunity for discussion in technical working groups so that a better understanding of treatment actions and natural attenuation evolves that was not present during the initial response. The potential downside of this strategy may be that some oiled shorelines may have to be treated again at a later time if the subsequently agreed criteria are more stringent than the originnal or interim criteria. Typically, based on understanding the weathering processes, the treatment criteria allow for natural attenuation of some residual oil that remains after treatment is completed.

\subsection{Treatment Option Considerations in the SRP Decision Support Tool}

The evaluation of treatment options during the planning and decision process in a shoreline response program considers a wide range of environmental, human use, and operational factors. The outputs from the MPRI SRP Decision Tool are based primarily on operational aspects and only identify potential environmental consequences at a high level (Table 1). Attachment A summarizes the four considerations defined in Table 1 for the most commonly applied shoreline treatment options; some less known or used options that are not covered in the Attachment include loose granular sorbents (peat and saw dust), many individual surface washing agents (Chen et al., 2019), dry ice application (Addassi et al., 2017) and laser treatment (Mateo et al., 2004).

\section{Response Options}

There exists a wide range of options for intervention to remove, clean, or treat oil deposited on shorelines when natural attenuation is not an acceptable strategy. The applicability, feasibility and effectiveness of each method is primarily a function of the oil type, the character of the substrate (shoreline type), and operational factors such as accessibility, sediment traction and bearing capacity, waste generation, and the level of effort required to implement the method. The decision to treat a section of oiled shoreline involves initial detection and delineation of surface and subsurface oil, an assessment of the expected persistence of the oil, and consideration of the potential environmental and socio-economic consequences of the treatment actions by comparison with natural attenuation.

There are a number of ways to define and group the range and character of shoreline treatment options, as described in manuals, guidelines, and other planning or training documents, although these are generally consistent with each other (NOAA, 1992; POSOW, 2013; IPIECA-IOGP, 2015; ECCC, 2016). The range of oil removal or treatment response options used for this 
Table 1. Definitions of the Operational Considerations in the SRP Decision Support Tool

\begin{tabular}{ll}
\hline $\begin{array}{l}\text { Potential Environmental } \\
\text { Consequences }\end{array}$ & $\begin{array}{l}\text { General ecological or geological effects of the method that may delay or otherwise affect recovery potential. An } \\
\text { incident- and location-specific NEBA or SIMA separately would consider effects or damages that may be caused } \\
\text { by the application of the method. }\end{array}$ \\
$\begin{array}{l}\text { Logistics Support and } \\
\text { Labor }\end{array}$ & $\begin{array}{l}\text { The overall level of effort and infrastructure required to support the treatment method and oil reduction targets. } \\
\text { Does not include location-specific access, staging, trafficability, waste management, and transportation factors. } \\
\text { Time to Completion } \\
\text { The operational time to implement and complete the activity to achieve the treatment target; except } \\
\text { bioremediation for which the implementation time scale typically is much shorter than the time to achieve the } \\
\text { treatment target. } \\
\text { The estimated relative volumes of oily and operational waste that would be generated and would require } \\
\text { Segregation, packaging, transfer, and disposal. }\end{array}$ \\
\hline
\end{tabular}

Fisheries and Oceans Canada project generally follow the Environment and Climate Change Canada (ECCC) categories, which are based on the operational character of the strategy.

In reality, most of the time shoreline treatment involves straightforward physical removal and disposal or washing to the adjacent waters. The purpose of this discussion supports the decision process with explanations of why and how the different commonly used and available response options contribute to accelerating shoreline recovery and to assess the current state-of-knowledge or understanding of those actions. Emphasis is placed on those options which are most commonly used (physical removal and physical washing) and those that currently are not as well accepted but that have the immediate potential for more widespread application, were they better understood (in-situ physical treatment methods).

\subsection{Physical Removal}

Direct physical removal of the oil is frequently a preferred option as this group of techniques is the quickest and most straightforward approach. Removal can be achieved either manually or mechanically, or by washing and flushing the oil from the shoreline to the adjacent water body.

\subsubsection{Manual and Mechanical Removal}

Physical removal methods may be simply using shovels, rakes, sieves, or sorbents manually to pick up oil, oiled debris, oiled sediment, cut oiled vegetation, vacuum pooled oil, or to wipe oil from bedrock or man-made surfaces (Table 2). Mechanically, earth-moving equipment, beach cleaning machines, or mobile vacuum systems can collect oil, oiled sediment or oiled debris. Although mechanical methods are quicker than manual removal techniques, they typically generate greater waste volumes (Owens et al., 2009).

The use of mechanical equipment is typically limited to sand and some mixed sediment beaches due to traction and trafficability limitations on well-sorted coarse sediment substrates (pebble, cobble, and boulder) and to accessibility, particularly for remote areas, although attempts have been made to design custom mechanical shoreline cleaners such as a mobile drum cleaner (SLRoss, 1984). An evaluation of mechanical beach-cleaning equipment through 1994 cataloged approximately fifty (50) separate machines, the majority of which were vacuum units, beach-cleaning machines, and mobile or trans- portable washing units (Taylor et al., 1994, 1995). No recent innovations have added to the basic mechanics of these types of equipment.

Table 2. Physical Removal Methods

\begin{tabular}{ll}
\hline & \multicolumn{1}{c}{ Physical - Removal } \\
\hline Manual & - Shoveling, scraping, sieving, trenching, wiping \\
Removal & - Vacuum recovery \\
& - Vegetation cutting \\
& - Passive manual sorbent deployment/recovery \\
Mechanical & - Multi-step: grader, bulldozer side-casting \\
Removal & - Mobile beach-cleaners (belt, drum, scraper, \\
& - Sieve) \\
& - Mobile vacuum trucks \\
& - Fixed on-site or nearby sediment treatment \\
& - Mechanical vegetation cutting (e.g. floating \\
& reed cutters, rice harvesters)
\end{tabular}

Typically, based on understanding the weathering processes, treatment criteria allow for natural attenuation of some residual oil that remains after treatment is completed. A consideration in this regard is that large-scale sediment removal may affect beach stability, particularly on coarse-sediment beaches where natural replacement rates for pebbles and cobbles may be slow if there is no natural replenishment (Owens, 2010). Alternative options, such as in-situ treatment, should be considered if sediment removal is a potential concern. The operations considerations for physical removal are summarized in Attachment A.

\subsubsection{Water Washing and Recovery}

Washing a shoreline with water that may be pressurized or heated to various degrees simply removes the oil from the shoreline environment and transfers it to the nearshore waters. In most instances that oil floats and the opportunity exists for mechanical recovery methods with booms, skimmers, or sorbents. However, typically little or no oil is recovered unless shoreline oil loadings are high. Washing actions that mix the oil with granular particles $(>1 \mathrm{~mm})$ may increase the oil residueparticle density so that the agglomerates do not float (Gustitus and Clement, 2017).

Experience has shown that ambient temperature and low pressure $(<25 \mathrm{psi}$ or $200 \mathrm{kPa})$ hydraulic washing methods are 
effective and preferred for light oils or unweathered medium and heavier oils. Heavy or weathered oils may require higher pressures to overcome viscosity and adhesion, which may dislodge attached live flora and fauna. Application of higher water pressure typically requires an assessment of the effectiveness of oil removal versus the potential ecological impacts. Very weathered oils may require an increase in water temperature as well as higher pressures, which may be biologically stressful. Washing oil from oiled wetlands is best conducted from a floating platform or standing seaward of the vegetation and using low pressures (Figure 1). Table 3 summarizes the washing methods and Table 4 provides ranges for common terms used to define washing methods. The pressures shown are at the nozzle. Applying Bernoulli's equation explains the decrease of water pressure with distance so that a nozzle with an outflow pressure of $50 \mathrm{psi}(\sim 350 \mathrm{kPa})$, typical for many washing operations, held approximately $2 \mathrm{~m}$ from a surface would be approximately $20 \mathrm{psi}(\sim 150 \mathrm{kPa})$ on contact.

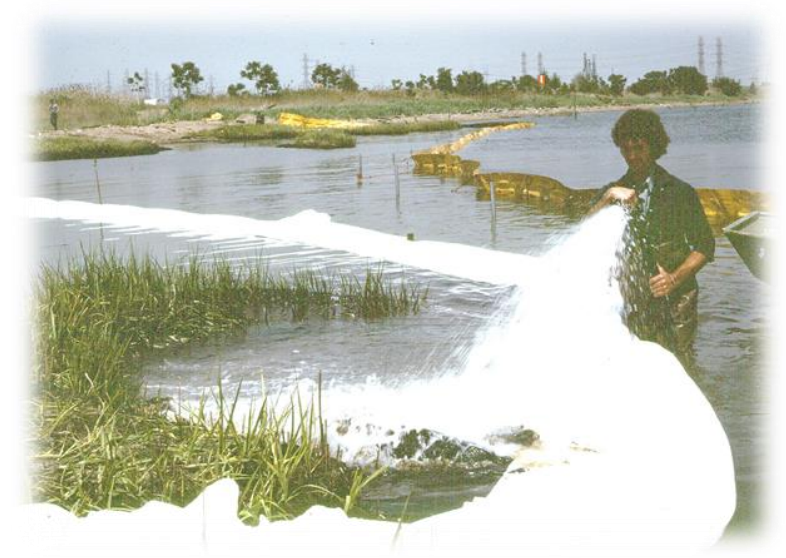

Figure 1. Low-pressure ambient temperature water flushing of experimentally oiled salt marsh vegetation.

Table 3. Physical Hydraulic Methods

\begin{tabular}{ll}
\hline Physical - Washing (with or without recovery) \\
\hline - Flooding & - Very low pressure header-hose or "deluge" \\
- Washing & - Low-pressure-ambient water flushing \\
& - High-pressure ambient water flushing \\
& - Low-pressure heated water flushing \\
& - High-pressure heated water flushing \\
\hline
\end{tabular}

Field experience has shown that, except for very weathered or heavy oils, as much as $90 \%$ of the stranded oil can be dislodged and removed in 4 to 5 passes with a low-pressure flush. This number of passes can be achieved at a very slow walking rate and can be most efficient if sufficient resources are available for two or more washing teams to sequentially leapfrog each other as treatment proceeds alongshore. Wellintentioned operators frequently tend to want to continue to apply the water stream to remove more oil but further flushing rapidly becomes less efficient and has the potential to harm flora and fauna. Clearly defining the treatment targets, particularly during the initial bulk oil removal phase, and supporting Opera- tions to ensure that they understand management expectations, are important elements during all stages of a shoreline response.

A common misconception exists regarding the term "steam cleaning", which is often used to describe "hot-water washing" or "hot-water high pressure washing". This is a misnomer as steam consists of the droplets or mist that form after water evaporates then condenses when the temperature of the water used for washing is warmer than the ambient air temperature. Steam generated from exposure to the air of heated water has a very low vapor pressure and may be at neither a hot temperature nor a high pressure. This was the case during the 1989 Exxon Valdez response, when washing was used at times during which air temperatures often were $30 \sim 40{ }^{\circ} \mathrm{C}$ lower than the heated water $\left(60^{\circ} \mathrm{C}\right)$, resulting in apparent steam cleaning (Nauman, 1991).

As noted in an earlier review (Owens and Sergy, 1996), there exists a knowledge gap to identify the optimum cleaning parameters for most washing techniques. An evaluation of water washing at that time concluded that the optimum combination of temperature and pressure is typically gained by trial and error or field testing during a cleanup operation (Taylor et al., 1995). The study noted that the factors that compound the difficulty of extrapolating results from one operation to another include shore zone substrate, oil type and state of weathering, availability of equipment for a range of temperature and pressure deliveries, and the varying seasonal and geographic sensitivity of the inhabitant organisms.

Very few studies have looked at the effects of varying water temperatures and pressures on shore zone flora and fauna. An example of one project that has partially helped to narrow the knowledge gap is a series of tests that identified the amounts of Bunker $\mathrm{C}$ that could be removed by increases of temperature and pressure and the tolerance ranges of plants and animals (algae and barnacles) to these changes (Mauseth et al., 1996). However, overall, this topic has received scant attention over the past decades and continues to remain a significant knowledge gap to support science-based shoreline treatment decisions.

\subsection{Physical In-Situ Treatment}

A separate group of physical treatment options is the use of physical in-situ treatment methods to accelerate natural weathering, dispersion and natural attenuation by biodegradeation. The in-situ treatment of oiled surface and/or subsurface sediments involves sediment mixing or sediment relocation methods which can be carried out quickly, efficiently and effectively with earth-moving equipment (API, 2016a, 2016b), or manually on a small scale. The underlying principle behind physical in-situ treatment is that the disturbance breaks apart stranded oil and/or exposes subsurface oil to increase the surface area to oil volume ratio and thereby promotes evaporation and biodegradation.

Mixing or sediment relocation in the presence of water and fine sediments $(<0.5 \mathrm{~mm})$ creates an oil-in-water emulsion which contains microbes. There are a variety of surface interaction mechanisms and processes that may be involved in a given situation (Boglaienko and Tansel, 2018). Not all of these mechanisms are fully understood at this time but there exists more 
Table 4. Summary of Temperature and Pressure Ranges for Hydraulic Washing

\begin{tabular}{|c|c|c|c|c|}
\hline \multirow[t]{2}{*}{ Tactic } & \multicolumn{2}{|c|}{ Water Pressure Range* } & \multicolumn{2}{|c|}{ Water Temperature Range } \\
\hline & $\mathrm{kPa}$ & psi & ${ }^{\circ} \mathrm{C}$ & ${ }^{\circ} \mathrm{F}$ \\
\hline Flooding/Deluge & $<150$ & $<20$ & ambient water & \\
\hline Low-pressure: ambient wash/flush & $<350$ & $<50$ & ambient water & \\
\hline Low-pressure: warm/hot wash/flush & $<350$ & $<50$ & $30 \sim 100$ & $90 \sim 210$ \\
\hline $\begin{array}{l}\text { High-pressure: ambient wash/flush } \\
\text { "pressure washing" }\end{array}$ & $\begin{array}{l}350 \sim 7,000 \\
>7,000\end{array}$ & $\begin{array}{l}50 \sim 1,000 \\
>1,000\end{array}$ & ambient water & \\
\hline High-pressure: warm/hot wash/flush & $350 \sim 7,000$ & $50 \sim 1000$ & $30-100$ & $90-210$ \\
\hline
\end{tabular}

than 50 years of research and abundant evidence of the outcome of the processes, which is the rapid formation of oil-particle aggregates in as little as a few seconds (Bragg and Yang, 1996; Boglaienko and Tansel, 2018). These products have been referred to variously as clay-oil flocs (COF) Bragg and Owens, 1995), oil-mineral aggregates (OMAs) Lee et al., 1998), oilSPM aggregates (OSAs) Sun et al., 2009), and oil particle aggregates (OPAs) Zhao et al., 2016). There has been some confusion and misconceptions in recent years concerning oil-sediment particle interactions which Gustitus and Clement (2017) as well as Boglaienko and Tansel (2018) attempted to rectify by defining the differences between the character and behavior of microscopic oil-fine particle aggregates and macroscopic oil residue-granular particle agglomerates (Owens et al., 2021a). This clarification is important to the decision process to explain the advantages of the physical in-situ treatment methods which can significantly accelerate dispersion and biodegradation on beaches.

The knowledge that the formation of microscopic oil-fine particle aggregates significantly enhances oil biodegradation rates supports the use of physical in-situ treatment options to accelerate shoreline recovery without potentially raising environmental concerns for the adjacent nearshore coastal water (Lee et al., 2003b). In addition, the increase of surface area to volume ratios exposes oil that would not otherwise be available for photochemical degradation. Importantly, in remote areas, these in-situ treatment methods do not require a high level of logistics support and involve little or no oily waste generation. Importantly, the applicability of this strategy has been demonstrated in a wide range of environments from arctic (Lee et al., 2003a) to tropical climates (Owens et al., 1995).

There are three options for physical in-situ treatment (Table 5) which are summarized below and described in greater detail in two API reports (API, 2016a, 2016b). Manual methods have only been occasionally reported to have been used on a significant scale (e.g., Moldan, 1997).

\subsubsection{Dry Sediment Mixing}

Dry mixing is conducted when the oil is exposed, such as during mid- or low-tide periods (Figure 2). An immediate consequence is that any light, volatile fractions are dispersed by evaporation. As the mixed area is inundated by the rising tidal water level, the newly exposed oiled sediments are subject to physical abrasion and dispersion by wave energy and to buoy- ancy partitioning, which can refloat the oil. Microscopic oilfine particle aggregate emulsions form rapidly (seconds to minutes) and typically remain in suspension and biodegrade quickly (days to weeks) in the water column. If the oil is mixed with larger grain size sands macroscopic oil residue-granular particle agglomerates are formed as the mixed area is inundated. These aggregates may not be dispersed into the water column but the increase in the surface area to volume ratio accelerates biodegradation rates. When considering the potential environmental consequences, the mixing action may increase the volume of oiled sediment and move oil deeper into the sediments so that the mixing depth should be within the normal zone of sediment reworking by wave action. There would be temporary sediment and habitat disturbance, which on exposed beaches would be of a lower magnitude than a storm wave event, but there would be no loss of sediment and sediment redistribution by wave action typically restores the beach form in one or two tidal cycles (Owens et al., 1991).

Table 5. Physical In-Situ Sediment Treatment Methods

\begin{tabular}{ll}
\hline Physical - In-Situ Treatment & \\
\hline$\bullet$ Sediment Mixing & $\bullet$ Dry \\
& - Wet \\
- Sediment Relocation & $\bullet$ Manual/mechanical \\
\hline
\end{tabular}

\subsubsection{Wet Sediment Mixing}

Wet mixing is conducted in the water when tides have immersed the oiled sediments to physically break apart the oil deposits, expose or release them to water and to generate microscopic oil-fine particle aggregate emulsions. This activity may be necessary or appropriate for a number of reasons, one of which is the lack of low tide water levels during daylight hours in winter months on southern British Columbia (Canada) and Washington state (USA) coasts. Wet mixing was used on a spill during December on the US coast in the Strait of Juan da Fuca and the released oil was contained and recovered (Miller, 1987). No data exist on the fate of oil from sediment mixing in marine environments but sample results from two freshwater (river) mixing projects with light products showed rapid downstream dispersion (Owens et al., 2000; Owens and Reimer, 2021). Any light, volatile fractions would be dispersed or dissolved. With light and medium oils typically microscopic oil-fine particle aggregate emulsions are quickly formed and physically disperse into the water column and are biodegraded. Weathered or heavy oil mixed with coarser sediment (sands) macroscopic oil 


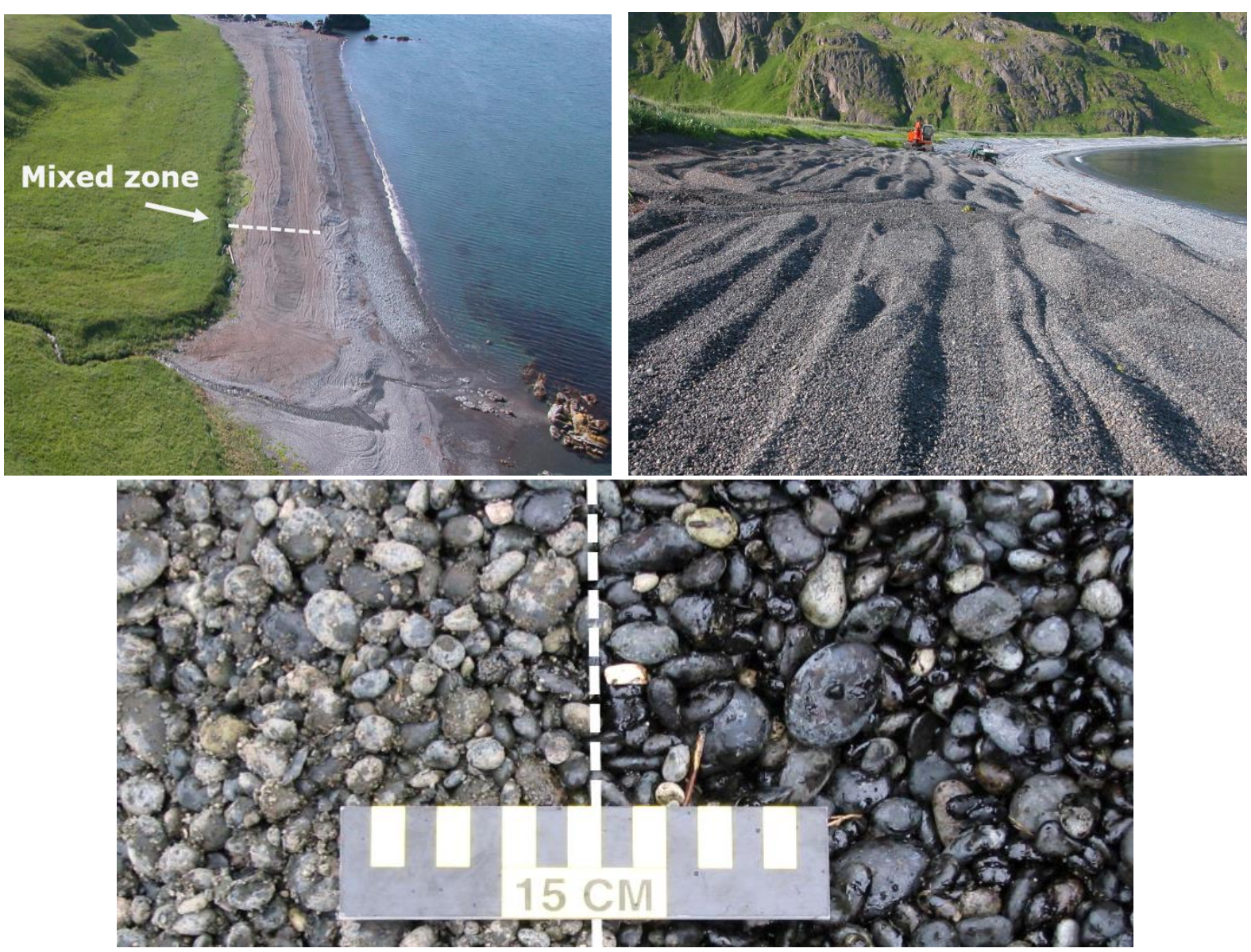

Figure 2. In-situ treatment of an oiled beach by dry sediment mixing at a remote beach site, Unalaska Island, Alaska. Bottom photo: oiled sediments before (right) and after (left) mixing.

Table 6. Biological Treatment Methods

\begin{tabular}{|c|c|}
\hline Biological & \\
\hline - $\quad$ Bioenhancement & $\begin{array}{l}\text { - Addition of non-living materials such as nutrients intended to increase the natural rate of biodegradation of } \\
\text { hydrocarbons by indigenous microorganisms. }\end{array}$ \\
\hline - Bioaugmentation & $\begin{array}{l}\text { Addition of microbes, with or without chemical supplements, to increase the rate of biodegradation over } \\
\text { that of natural indigenous microorganisms and conditions. }\end{array}$ \\
\hline - $\quad$ Phytoremediation & - Application of fungi or plants \\
\hline
\end{tabular}

residue-granular particle agglomerates are formed that may not disperse into the water column (Gustitus and Clement, 2017). There would be temporary sediment and habitat disturbance but no loss of sediment and sediment redistribution by wave action would be rapid.

\subsubsection{Sediment Relocation}

The movement of oiled sediments from one location to another is intended to accelerate the attenuation of the oil by (a) evaporation, (b) physically breaking apart the oil deposits, (c) exposing the oiled sediment to wave action, and (d) the formation of microscopic oil-fine particle aggregate emulsions. Oil was stranded on many beaches in the supratidal zone above the limit of normal wave action during spring high tides following the Exxon Valdez incident and these sediments were mechanically redistributed down the beaches into the intertidal zone; this activity was referred to as "berm relocation" at the time (Owens et al., 1991). Accelerated attenuation by sediment relocation does not require wave energy, although the method is sometimes referred to incorrectly as "surf washing" (Fichaud and Loubnan, 2008; Kerambrun et al., 2014). In areas with wave (or "surf") action then sediment relocation accelerates the physical breakdown and dispersion of oil into the water column. The relative significance of wave action to break down stranded oil and aggregate emulsion formation in different energy environments is discussed by Owens et al. (2021a). As noted above, weathered or heavy oil mixed with coarser sediment (sands) may form macroscopic oil residue-granular particle agglomerates that may not disperse into the water column. 
Temporary sediment and habitat disturbance on exposed beaches would be of a lower magnitude than a storm wave event. No sediments are removed from the beach and normal sediment redistribution typically restores the beach form in one or two tidal cycles (Owens et al., 1991).

\subsection{Biological Treatment}

The third category of removal treatment options involves biological techniques (Table 6) to accelerate rates of oil biodegradation. Naturally occurring micro-organisms (bacteria) use oxygen to convert hydrocarbons into water and carbon dioxide (Sergy et al., 1993). This process usually occurs at the oil/water interface and is limited primarily by the availability of oxygen and nutrients and the exposed surface area of the oil. The rate of biodegradation can be accelerated if one or all of these three limiting factors can be changed. Bioaugmentation and phytoremediation techniques have had limited use historically for the treatment of oil on shorelines. Bioremediation is applicable for treating light and medium oils on bedrock and beaches and can be used where there is light oiling or on residual oil ("polishing") after mobile or bulk oil has been removed from the shoreline. Off-site treatment of oiled sediments is similar to land farming technology and could involve bioaugmentation and/or phytoremediation as well as adding nutrients. Bioremediation is not a short-term solution as the degradation process may take days to weeks.

\subsubsection{Bioenhancement}

The addition of nutrients, sometimes referred to as biostimulation, is intended to accelerate the rate of natural biodegradation (Venosa et al., 1996; Zhu et al., 2001; Geng et al., 2015; Boufadel et al., 2016). Many types of fertilizers have proven efficacious; however, oleophilic and slow-release formulations require less frequent applications and are more efficient from an operational perspective. Biodegradation preferentially removes the "oiliest" compounds of spilled oil and may leave a residue that readily flakes off as small asphaltic flakes (Atlas and Bragg, 2013). Biodegradation may be considered a "polishing" method for residual oil after the completion of physical bulk oil removal or as a primary option in combination with in-situ sediment mixing (Sergy et al., 2003). Bioremediation, through the addition of fertilizers to the surface of oiled shorelines, during the Exxon Valdez response accelerated natural biodegradation rates by three to five times without any toxicity to biota or other adverse environmental effects (Atlas and Bragg, 2013).

\subsubsection{Bioaugmentation}

Bioagumentation is the process whereby the indigenous microbial population is supplemented by the addition of living microbes, and possibly chemical agents, to accelerate natural attenuation rates (Vogel and Walter, 2001; Major et al., 2002; Nikolopoulou et al., 2013). In most circumstances the need for additional microbes is unlikely as oil degrading microbes are quite ubiquitous and local indigenous populations will natural- ly respond to an increase in hydrocarbons or can be stimulated with bioenhancement.

\subsubsection{Phytoremediation}

Phytoremediation consists of using vegetation to accelerate biodegradation. The method may be appropriate where plants are native to the shore zone. The use of marsh-grasses has met with some success (Dowty et al., 2001; Lin and Mendelssohn, 2009; Yavari et al., 2015). Plants appear to have limited hydrocarbon degradation potential on their own, but their roots are believed to stimulate subsurface microbial biodegradation by delivering oxygen and other nutrients, and in naturally "mixing" compacted sediments. Many fungi are able to degrade polycyclic aromatic hydrocarbons, but their role in the marine environment is usually far-outstripped by bacteria.

\subsection{Chemical Treatment}

Oil removal also can be achieved by means of another group of options that involve the controlled application of chemical products to the oil. The two primary classes of chemical treatment agents are dispersants and surface washing agents. Dispersants promote the formation of small droplets, which disperse into the water column and become more bioavailable. Surface washing agents promote the separation or partitioning of the oil from the substrate for recovery on the water surface (Walker et al., 1995; Chen et al., 2019). Other chemical treatment options such as solidifiers or visco-elastic agents (Table 7) have not been proven to be effective or efficient primarily as these involve large amounts of the agent and the application (mixing process) is labor intensive, slow, and not suited to the use of mechanized techniques. Generally, the use of any chemicals on shorelines requires permitting and approval under specific application conditions. A NEBA is typically used to gauge the benefits and potential drawbacks of the options under consideration.

Many other chemical treatments have been tried or tested, such as solidifiers (Owens et al., 1987; Walker et al., 1995) and dry ice (Addassi et al., 2017); however, these typically are not considered for large-scale applications but rather for site-specific situations with small amounts of oil.

\subsubsection{Dispersant Agents}

Dispersants could be applied to shorelines in conjunction with flushing or washing as water movement is required to allow the rapid dilution of dispersed oil. To facilitate the transfer of dispersed oil into nearshore waters, their use should be restricted to areas with high wave action and tidal energy. This technique could be applied only upon NEBA support and approval of national and local regulations (IPIECA-IOGP, 2015); extensive toxicology testing is also required to obtain approval for use. More discussions can be found in literature (e.g., Fingas, 2014).

\subsubsection{Surface Washing Agents}

Unlike dispersant use, the intent of applying surface treat- 
Table 7. Chemical Treatment Methods

\begin{tabular}{ll}
\hline Chemical & \\
\hline - Surface Treatment Agents/Recovery & - Solvents or other agents with flooding or flushing ("shoreline cleaners") \\
& - Washing in concrete mixer truck or tank \\
& - Herders \\
& - Solidifier or visco-elastic agents \\
& - Dry ice \\
& - Passive mineral or organic sorbents/recovery \\
- Surface Washing Agents/without Recovery & - Dispersant \\
- Stabilization or Coating/without Recovery & - Passive mineral or organic adsorbents to accelerate in-situ attenuation \\
\hline
\end{tabular}

ment agents is to collect the released oil instead of dispersing it, either directly using sorbents or flushing it to a collection point for recovery by skimmers or other physical methods. The multifunctional action of surface washing agents reduces the viscosity of the oil and its interfacial tension to promote lifting of the oil from substrates without causing its dispersion into the water column. Benefits of using surface washing agents include high oil removal efficiency (especially for heavily weathered oils), ambient temperature and low-pressure requirements for flushing, and lower disturbance to the shorelines (Bi et al., 2020). Over the past three decades, surface washing agents have been successfully applied in many spill incidents and field tests; for instance, Corexit 9580 was applied during the Exxon Valdez response to test the viability to treat oiled shorelines (Fiocco et al., 1991).

\subsubsection{Stabilization or Coating}

Some chemical agents such as lime can be used to stabilize or solidify oil on the beach surface to prevent it from spreading (NOAA, 1992). These agents intensify polymerization of the hydrocarbon molecules; the oil can be rendered visco-elastic but still fluid, viscous, or semisolid. This technique reduces the solubility of the light fractions by fixing them into the polymer, leading to lower exposure both to air and water. It has been observed that the application of solidifiers effectively reduce total petroleum hydrocarbon concentration and leaching (Ivshina et al., 2015). Such techniques may be applicable on unvegetated shorelines of low permeability where heavy oil has pooled on the beach surface because the congealed oil may adhere to vegetation and wildlife, enhancing the smothering effect of oil on intertidal organisms (NOAA, 1992). Field trials using solidifiers demonstrated that the application and recovery effort is very labour intensive and likely not practicable on anything but very small scales (Owens et al., 1987).

\subsection{Thermal Treatment}

The fourth group of options involves thermal treatment of the oil (Table 8). Burning has been used to remove combustible materials such as oiled woody debris or in vegetated oiled areas, where the oil is sufficiently thick and where vegetation provides additional fuel for sustained combustion (Lin et al., 2005; ASTM, 2010; Michel and Rutherford, 2013). However, burning is not a feasible option on beaches and attempts to ignite stranded oil on sediments have been unsuccessful (Owens et al., 1987).
Table 8. Thermal Treatment Methods

\begin{tabular}{ll}
\hline Thermal & \\
\hline$\bullet$ Burning & $\bullet$ Marsh grasses \\
& $\bullet$ Debris \\
- Incineration & $\bullet$ On site \\
& $\bullet$ Off-site \\
\hline
\end{tabular}

Incineration involves removal of the oil from the beach into a purpose-built machine or device and typically requires a source of heat for ignition and sustained combustion. One study has evaluated the use of lasers to eliminate oil on hard substrates, a technique that has been used on stone buildings and walls (Mateo et al., 2004). As with other non-traditional methods, this option could have specific applications.

\section{Discussion and Conclusions}

Shoreline studies during and following the Exxon Valdez spill in 1989 related to the behavior and fate of stranded oil and the development of standardized shoreline survey protocols were a watershed that changed decision-maker's perspective on the various shoreline treatment options. Two key approaches implemented during that response were the development and adoption of the Shoreline Cleanup Assessment Technique (SCAT) (ECCC, 2018) and the inclusion of the concept of the Net Environment Benefit (NEB) to address the potential consequences of shoreline treatment decisions (Baker, 1995; IPIECA-API-IOGP, 2017).

There have been several important advances since a series of reviews in the mid-1990s related to the treatment of oiled shorelines (Taylor et al., 1995; Walker et al., 1995; Owens and Sergy, 1996). The most potentially valuable of these advances, in terms of supporting the shoreline treatment decision process, have been:

- A large number of studies on the fine particle-oil interaction processes and the controlling variables; summarized recently by Gustitus and Clement (2017) as well as Boglaienko and Tansel (2018). This knowledge has radically improved the scientific basis to support the decision process for the physical in-situ treatment of oiled sediments.

- Knowledge gained from the In-situ Treatment of Oiled Sediment Shorelines (ITOSS) Program in Svalbard; an experimental oil spill field study designed specifically to in- 
vestigate sediment mixing and relocation in a low waveenergy environment (Sergy et al., 2003; Prince et al., 2003).

- Shoreline program management lessons learned from the Deepwater Horizon response; which were more about the decision process and the implementation of those decisions than actual shoreline treatment methods (IPIECAIOGP, 2020; Owens and Santner, 2021).

- The API "state-of-the-art" reports regarding the in-situ treatment of oiled beaches and marshes (Michel and Rutherford, 2013; API, 2016a, 2016b).

- The development of a Job Aid to estimate the types and volumes of waste that could be generated by the different shoreline treatment methods for different oil types and loadings on a range of shore types (Owens et al., 2009). Importantly, this Job Aid provides insights into the waste stream consequences of decisions regarding shoreline treatment options.

Notwithstanding these advances, there remain significant gaps with respect to how and why the different response methods contribute to accelerating shoreline recovery and the po- tential consequences of these actions. The knowledge gaps that relate to stranded oil translocation processes and pathways during weathering and attenuation are discussed in a companion review in this issue (Owens et al., 2021a) and the current level of understanding regarding the options to accelerate the recovery of oiled shorelines are discussed below.

Table 9 summarizes the treatment options that can accelerate the oil weathering processes. Evaporation, dissolution, oilcolloid particulate aggregation by OcPA formation (Owens et al., 2021a), biodegradation, and photodegradation are in-situ weathering processes that can act directly on exposed surface oil. Physical actions that lead to the disintegration of oil deposits (sediment mixing or relocation) or induce remobilization (buoyancy partitioning) accelerate each of these processes by increasing the surface area to oil volume ratio. Washing methods (flooding and flushing) are a commonly used treatment method and can accelerate each of the weathering and attenuation processes; however, as discussed above (Section 3.1.2) this is one of the least understood methods in terms of the behavior and fate of oil that is broken down and mobilized. The

Table 9. Summary of Treatment Methods that Accelerate Weathering Processes

\begin{tabular}{ll}
\hline Shoreline Oil Weathering Process & Treatment Methods That Accelerate Weathering \\
\hline Volatilization: Evaporation and Dissolution & Sediment Mixing/Relocation \\
& Surface Washing Agents \\
& Flooding, Flushing and Washing \\
Chemical Break Down and Physical Disintegration - & Sediment Mixing/Relocation \\
Dispersion by Waves/Currents & Flooding, Flushing and Washing \\
Buoyancy Partitioning - Dispersion & Surface Washing Agents, Dispersants \\
& Flooding \\
In-Situ Transformation: Biodegradation or & Bioremediation \\
Photodegradation & Dispersant Application \\
& Washing Agents \\
\hline
\end{tabular}

Table 10. Summary of State of Knowledge of Oiled Shoreline Treatment Methods (see text for explanation of the symbols)

\begin{tabular}{|c|c|c|c|c|}
\hline Methods & $\begin{array}{l}\text { Understanding of } \\
\text { Operations and } \\
\text { Implementation }\end{array}$ & $\begin{array}{l}\text { Understanding of } \\
\text { Transformation and } \\
\text { Translocation }\end{array}$ & $\begin{array}{l}\text { Understanding of } \\
\text { Toxicological Effects }\end{array}$ & $\begin{array}{l}\text { Supported by Peer } \\
\text { Reviewed Scientific } \\
\text { Literature }\end{array}$ \\
\hline \multicolumn{5}{|l|}{ Biological } \\
\hline Bioenhancement & $\Delta \Delta \Delta$ & $\Delta \Delta \Delta$ & $\Delta \Delta \Delta$ & $\Delta \Delta \Delta$ \\
\hline Bioaugmentation & ++ & $\Delta \Delta \Delta$ & - & $\bullet$ \\
\hline Phytoremediation & ++ & $\bullet$ & ++ & $\bullet$ \\
\hline \multicolumn{5}{|l|}{ Chemical } \\
\hline Surface Washing Agents & ++ & $\bullet$ & ++ & $\bullet$ \\
\hline Dispersant Agents & ++ & $\bullet$ & ++ & $\bullet$ \\
\hline \multicolumn{5}{|l|}{ Physical } \\
\hline $\begin{array}{l}\text { Manual/Mechanical } \\
\text { Removal }\end{array}$ & $\Delta \Delta \Delta$ & $\Delta \Delta \Delta$ & $\Delta \Delta \Delta$ & $\Delta \Delta \Delta$ \\
\hline $\begin{array}{l}\text { Flooding, Flushing and } \\
\text { Washing }\end{array}$ & $\Delta \Delta \Delta$ & & & \\
\hline Sediment Dry Mixing & $\Delta \Delta \Delta$ & $\Delta \Delta \Delta$ & ++ & $\Delta \Delta \Delta$ \\
\hline Sediment Wet Mixing & $\Delta \Delta \Delta$ & $\Delta \Delta \Delta$ & ++ & $\Delta \Delta \Delta$ \\
\hline Sediment Relocation & $\Delta \Delta \Delta$ & $\Delta \Delta \Delta$ & ++ & $\Delta \Delta \Delta$ \\
\hline \multicolumn{5}{|l|}{ Thermal/Combustion } \\
\hline Burning Oiled Material & $\Delta \Delta \Delta$ & $\Delta \Delta \Delta$ & $\Delta \Delta \Delta$ & $\Delta \Delta \Delta$ \\
\hline Incineration & $\Delta \Delta \Delta$ & $\Delta \Delta \Delta$ & $\Delta \Delta \Delta$ & $\Delta \Delta \Delta$ \\
\hline
\end{tabular}


in-situ physical treatment methods (sediment dry/wet mixing and sediment relocation) similarly accelerate each of these processes, except buoyancy partitioning, by increasing the surface area to oil volume ratio; however, the consequences of these methods are well understood due to the many field and laboratory studies that have been conducted to investigate the behavior and fate of the released oil (Sergy et al., 2003; API, 2016a, 2016b).

\subsection{Shoreline Intervention Knowledge Gaps and Recommendations for Future Studies}

Table 10 summarizes the results of this review and incorporates a broader understanding of the scientific literature basis for oiled shoreline response methods to accelerate the recovery of oiled shorelines and the consequences of their use. As noted above and indicated in this table, very little of the current knowledge on this subject matter resides in peer reviewed publications, other than treatment topics that are associated with oil-fine sediment particle processes and bioenhancement.

The symbols $(\Delta+\bullet)$ indicate the degree to which that topic is currently understood, in terms of the environmental (NEBA) and operational (SIMA) decision process, as a result of specific scientific investigations or from real-world experience. Three triangles indicate a high level of confidence $(\Delta \Delta$ $\Delta)$, two crosses indicate an adequate level of confidence $(++)$, and a single dot indicates a basic understanding with room for improvement by future studies $(\bullet)$. The dark shading indicates a poorly understood topic with respect to the decision process.

The operational implementation of the treatment methods is generally well understood but very few are well documented or reported in science-based peer reviewed publications. In summary:

- The bioenhancement processes are well studied and reported in many science-based peer reviewed publications.

- The physical removal methods are well documented, primarily in non-peer reviewed publications as few sciencebased studies have looked at manual or mechanical removal.

- In-situ sediment mixing and relocation methods and the associated oil fine-sediment particle emulsification processes are well documented in peer and non-peer reviewed science publications. The current Canadian federal government Multi-Partner Research Initiative (MPRI) oil translocation studies are designed to generate science-based peer reviewed publications and to significantly advance the acceptance of dry/wet mixing and sediment relocation. A separate MPRI shoreline treatment study is focused specifically on surface washing agents.

- There exists a fundamental knowledge gap for the flooding, flushing, and washing methods with respect to the behavior and attenuation of oil translocated to the water from shorelines by these methods.

Understanding the expected and unexpected (unintended) consequences of intervention is a critical element of the decision process. The range of consequences includes temporary, long-term, or permanent habitat modifications as well as sedimentological and toxicological effects of the intervention actions. Some consequences may be short-term and within the range of normal physical or ecological variability, as is typically the case for most activities, including sediment mixing and sediment relocation.

\subsection{Concluding Remarks}

A review conducted 25 years ago (Owens and Sergy, 1996) defined several shoreline response issues that could best help a response manager or decision-maker to select an appropriate course of action. High priority issues that warranted immediate research studies at that time were:

- the role and effectiveness of in-situ cleanup techniques, such as surf washing,

- the development of procedures for determining and documenting the fine particle-oil interaction process and the controlling variables,

- $\quad$ optimizing the effectiveness of hydraulic cleanup techniques, and

- the development of appropriate response actions for low API (gravity) oils (LAPIO) or Group V oils.

The first two items have been addressed to the degree that sufficient knowledge and understanding has been generated to now support the decision process. As is argued in this discussion, the knowledge gap remains regarding washing cleanup options. On the fourth item, in North America, the emphasis has shifted from LAPIO or Group V oils to dilbit (diluted bitumen) oils, which can be considered in the same family of oils in terms of shoreline treatment.

Globally, the most common shoreline treatment activity is simple physical removal by manual or mechanical cleanup methods and off-site disposal. The explanation for this lies in the fact that this method is typically quick, easy, and requires no special skill sets or dedicated equipment. In remote areas, where logistics support is a primary issue, the level of effort required to treat the shoreline manually and the waste stream generated by mechanical methods become important factors in the decision process. The second most common treatment method is low-pressure flushing or washing. A concern, which has not changed in 25 years regarding this hydraulic method, is that typically little or no oil is recovered, unless the oil loading on the shore is very high, and that the fate of the oil is largely unknown. Some of the oil may be broken down and dispersed in the water column and biodegraded whereas oil residue-sediment aggregates may sink if the sediments are granular $(>1$ $\mathrm{mm}$ ) or coarser. Other treatment options have been applied from time to time, typically for small amounts of oil, but are rarely used on a large scale. One exception is the bioremediation strategy that was applied to treat over 2,000 sites on over $120 \mathrm{~km}$ of lightly oiled shorelines in Alaska in 1989 1991 (Bragg et al., 1994; Atlas and Bragg, 2013).

The current MPRI studies have been designed to investigate (1) physical in-situ treatment methods in the absence of wave energy and (2) surface washing agents in order to significantly advance the understanding of these options. Both sets of 
methods are currently considered "non-standard" and therefore require approval before they can be implemented. This acceptance and approval sometimes may be a lengthy process. To this end, the MPRI Shoreline Response Program (SRP) Decision Support Tool is being developed to enhance the quality of strategic planning regarding shoreline response by presenting decision makers and planners with a view of the potential consequences of the options regarding shoreline treatment. This review in intended to support the development of that Decision Support Tool.

\section{References}

Addassi, Y.N., Yamamoto, J., and Cullen, T.M. (2017) The Refugio Oil Spill Response: Case Study and Lessons' Learned/Best Practices for the Future. International Oil Spill Conference Proceedings, 2017(1), 104-123. https:// doi.10.7901/2169-3358-2017.1.104

API, (2016a). Shoreline In Situ Treatment (Sediment Mixing and Relocation) Fact Sheet. American Petroleum Institute, Technical Report 1155-2, Washington DC, pp 20.

API, (2016b). Shoreline In Situ Treatment (Sediment Mixing and Relocation) Job Aid. American Petroleum Institute, Technical Report 1155-3, Washington DC, pp 26.

ASTM, (2010). Standard Guide for In-Situ Burning of Oil Spills in Marshes. ASTM Standard F2823--15, ASTM International, Conshohocken PA, pp 5.

Atlas, R.M. and Bragg, J.R. (2013). Removal of Oil from Shorelines: Biodegradation and Bioremediation. Oil in the Environment, 176196. https://doi.10.1017 /CBO9781139225335.013

Baker, J.M. (1995). Net Environmental Benefit Analysis for Oil Spill Response. Proc. International Oil Spill Conference, American Petroleum Institute, Washington, D.C., Publication No. 4620, 611614. https://doi.10.7901/2169-3358-1995-1-611

Baker, J.M., Little, D.I., and Owens, E.H. (1993). A Review of Experimental Shoreline Oil Spills. Proc. International Oil Spill Conference, American Petroleum Institute, Washington, D.C., Publication No. 4580, pp 583-590. https://doi.10.7901/2169-3358-1993-1-583

Boufadel, M.C., Geng, X., and Short, J. (2016). Bioremediation of the "Exxon Valdez" oil in Prince William Sound beaches. Marine Pollution Bulletin, 113 (1-2), 156-164. https://doi.10.1016/j.marpol bul.2016. 08.086

Boglaienko, D. and Tansel, B., (2018). Classification of oil-particle interactions in aqueous environments: Aggregate types depending on state of oil and particle characteristics. Marine Pollution Bulltin, 133, 693-700. https://doi.org/10.1016/j.marpolbul.2018.06.037

Bragg, J.R., Prince, R.C., Harner, E.J., and Atlas, R.M., (1994). Effectiveness of Bioremediation for the Exxon Valdez Oil Spill. Nature, 368. https://doi.10.1016/j. marpolbul.2016.08.086

Bi, H., An, C., Chen, X., Owens, E., and Lee, K. (2020). Investigation into the oil removal from sand using a surface washing agent under different environmental conditions. Journal of Environmental Management, 275, 111232. https://doi.10.1016/j.jenvman.2020.11 1232

Chen, Z.K., An, C.J., Boufadel, M., Owens, E., Chen, Z., Lee, K., Cao, Y., and Cai, M. (2019). Use of Surface-Washing Agents for the Treatment of Oiled Shorelines: Research Advancements, Technical Applications and Future Challenges. Chemical Engineering Journal, 391, 123565. https://doi.org/10.1016/j.cej.2019.123565

Dowty, R.A., Shaffer, G.P., Hester, M.W., Childers, G.W., Campo, F.M., and Greene, M.C. (2001). Phytoremediation of Small-scale Oil Spills in Fresh Marsh Environments: A Mesocosm Simulation. Marine Environmental Research, 52 (3), 195-211. https://doi.10. 1016/S0141-1136(00)00268-3

ECCC, (2016). A Field Guide to Oil Spill Response on Marine
Shorelines. Prepared and provided by Polaris Applied Sciences, and S3 Environmental Inc., for Environment and Climate Change Canada, Ottawa ON, pp 223.

ECCC, (2018). Shoreline Cleanup Assessment Technique (SCAT) manual, Third edition. Prepared and provided by Triox Environmental Emergencies, Owens Coastal Consultants, Environmental Mapping Ltd., for Environment and Climate Change Canada, Ottawa ON, pp 181. http://publications.gc.ca/site/eng/9.855598/pub lication.html

Fichaud, B. and Loubnan, B. (2008). Massive Use of Berm Relocation and Surfwashing during the 2006 Jyeh Oil Spill (Lebanon). Proc. International Oil Spill Conference. American Petroleum Institute, Washington, D.C., 221-338. https://doi. 10.7901/2169-3358-2008$1-331$

Fingas, M. (2014) A Review of Literature Related to Oil Spill Dispersants 2011-2014. Prince William Sound Regional Citizens' Advisory Council (PWSRCAC) Anchorage, Alaska.

Fiocco, R.J., Canevari, G.P., Wilkinson, J.B., Jahns, H.O., Bock, J., Robbins, M., and Markarian, R.K. (1991). Development of COREXIT 9580-A chemical beach cleaner. Proc. International Oil Spill Conference, American Petroleum Institute, Washington, D.C., Publication No. 4529, 395-400. https://doi.10.7901/2169-3358-1991-1395

Geng, X., Boufadel, M.C., Lee, K., Abrams, S., and Suidan, M. (2015). Biodegradation of subsurface oil in a tidally influenced sand beach: Impact of hydraulics and interaction with pore water chemistry. Water Resources, 51, 3193-3218. https://doi.org/10.1002/2014WR 016870

Gustitus, S.A. and Clement, T.P. (2017). Formation, Fate and Impacts of Microscopic and Macroscopic Oil-Sediment Residues in Nearshore Marine Environments: A Critical Review. Reviews of Geophysics, 55, (4), 1130-1157. https://doi.10.1002/2017RG000572

IPIECA-IOGP, (2015). A guide to shoreline clean-up techniques. Good practice guidelines for incident management and emergency response personnel. IOGP Report 521, London UK, pp 65. (revised 2016). https://www.giwacaf.net/en/publications/shoreline-response -ipieca-gpg

IPIECA-IOGP, (2015). Response strategy development using net environmental benefit analysis (NEBA). Good practice guidelines for incident management and emergency response personnel. IOGP Report 527, London UK, pp 39. (revised 2016) https://www.giwacaf. net/en/publications/neba-ipieca-gpg

IPIECA-API-IOGP, (2017). Guidelines on implementing spill impact mitigation assessment (SIMA). A technical support document to accompany the IPIECA-IOGP guidance on net environmental benefit analysis (NEBA). IOGP Report 593, London UK, pp 42. https://www.ipieca.org/media/4867/guidelines_on_implementing spill_impact_mitigation_assessment_sima_2017.pdf

IPIECA-IOGP. (2020). Shoreline Response Programme Guidance. A technical support document to accompany the IPIECA-IOGP guidance on oiled shoreline assessment and shoreline clean-up techniques. IOGP Report 635, London UK. https://www.ipieca.org/resour ces/good-practic e/shore lineresponse-programme-guidance/

IPIECA-IOGP. (2018). Guidelines on Implementing Spill Impact Mitigation Assessment (SIMA). A technical support document to accompany the IPIECA-IOGP guidance on net environmental benefit analysis (NEBA). IOGP Report 593, London UK. http://www. ipieca.org/resources/awareness-briefing/guidelines-on-implementi ng-spill-impa ct-mitigation-assessment-sima/

Ivshina, I.B., Kuyukina, M.S., Krivoruchko, A.V., Elkin, A.A., Makarov, S.O., Cunningham, C.J., and Philp, J.C. (2015). Oil spill problems and sustainable response strategies through new technologies. Environmental Science: Processes and Impacts, 17(7), 1201-1219. https://doi.10.1039/c5em00070j

Kerambrun, L., Cariou, G., and Laruelle, F. (2014). The TK BREMEN Incident. Surfwashing Operations as a Clean-up Strategy to Prevent Oil Entering a Small Estuary, the Etel Ria (France) Proc. $37^{\text {th }}$ Arctic 
and Marine Oilspill Programme (AMOP) Technical Seminar, Environment Canada, Ottawa ON, 714-721.

Lee, K., Stoffyn-Egli, P., Tremblay, G.H., Owens E.H., Sergy, G.A., Guénette, C.C., and Prince, R.C. (2003a). Oil-Mineral Aggregate Formation on Oiled Beaches: Natural Attenuation and Sediment Relocation. Spill Science and Technology sp. Bulletion, 8(3), 285296. https://doi.10.1016/S1353-2561(03)00042-2

Lee, K., Wohlgeschaffen, G., Tremblay, G.H., Johnson, B.T., Sergy, G.A., Prince, R.C., Guénette, C.C., and Owens E.H. (2003b). Toxicity Evaluation with the Microtox Test to Assess the Impact of In situ Oiled Shoreline Treatment Options: Natural Attenuation and Sediment Relocation. Spill Science and Technology sp. Bulletion, 8(3), 273-284. https://doi.10.10 16/S1353-2561(03)00039-2

Lin, Q., Mendelssohn, I.A., Bryner, N.P., and Walton, W.D., (2005). In situ burning of oil in coastal marshes. 1. Vegetation recovery and soil temperature as a function of water depth, oil type, and marsh type. Environmental Science and Technology, 39(6), 1848-1854. https:// doi.10.1021/es049063y

Lin, Q. and Mendelssohn, I.A. (2009). Potential of restoration and phytoremediation with Juncus roemerianus for diesel-contaminated coastal wetlands. Ecological Engineering, 35(1), 85-91. https://doi org /10.1016/j.ecoleng.2008.09.010

Major, D.W., McMaster, M.L., Cox, E.E., Edwards, E.A., Dworatzek, S.M., Hendrickson, E.R., Starr, M.G., Payne, J.A., and Buonamici, L.W. (2002). Field demonstration of successful bioaugmentation to achieve dechlorination of tetrachloroethene to ethane. Environmental Science and Technology, 36 (5), 106-5116. https://doi.10.1021/es 0255711

Mateo, M.P., Nicolas, G., Pinon, V., Alvarez, J.C., Ramil. A., and Yanez, A. (2004). Laser Cleaning of Prestige Tanker Oil Spill on Coastal Rocks Controlled by Petrochemical Analysis. Analytical Chemical Acta, 524(1-2), 27-32. https://doi.10. 1016/j.aca.2004. 04.066

Mauseth, G.S., Erickson, G.M., Bronco, S.L., and Sergy, G.A. (1996). Optimizing Hydraulic Cleaning Techniques for Oiled Course Sediment Beaches. Proc. 19th Arctic and Marine Oilspill Programme (AMOP) Technical Seminar, Environment Canada, Ottawa ON, 1159-1171.

Michel, J. and Rutherford, N. (2013). Oil Spills in Marshes: Planning and Response Considerations. American Petroleum Institute, Washington, DC, and National Oceanic and Atmospheric Administration, Seattle, WA, pp 126.

Miller, J.A. (1987). Beach Agitation for Crude Oil Removal from Intertidal Beach Sediments. Proc. International Oil Spill Conference, American Petroleum Institute, Washington, DC, Publication No. 4452, 85-90. https://doi.10.7901/2169-3358-1987-1-85

Moldan, A. (1997). Response to the Apollo Sea Oil Spill, South Africa. Proc. International Oil Spill Conference, American Petroleum Institute, Washington DC, Publication No.4651, 777-781. https:// doi.10.7901/2169-3358-1997-1-777

Nauman, S.A. (1991). Shoreline Cleanup: Equipment and Operations. Proc. International Oil Spill Conference, American Petroleum Institute, Washington DC, Publication No. 4529(1), 141-147. https:// doi.10. 1016/j.marpolbul.2013.04.007

Nikolopoulou, M., Pasadakis, N., and Kalogerakis, N. (2013). Evaluation of Autochthonous Bioaugmentation and Biostimulation during Microcosm-simulated Oil Spills. Marine Pollution Bulletin, 72(1), 163-173. https://doi.10.1016/j.marpolbul.2013.04.007

NOAA. (1992). Shoreline Countermeasures Manual - Temperate Coastal Environments. Hazardous Materials Response and Assessment Division, Seattle WA, pp 90. https://response.restoration.noa a.gov/sites/default/files/shoreline_countermeasures_temperate.pdf

Owens, E.H. (2010). Shoreline Response and Long-Term Oil Behaviour Studies following the 1970 "ARROW" Spill in Chedabucto Bay, NS. Proceedings $33^{\text {rd }}$ Arctic and Marine Oilspill Programme (AMOP) Technical Seminar, Environment Canada, Ottawa ON,
207-221.

Owens, E.H., Davis, R.A., Jr., Michel, J., and Stritzke, K., (1995). Beach cleaning and the role of technical support in the 1993 Tampa Bay spill. Proc. International Oil Spill Conference, American Petroleum Institute, Washington, DC, Pub. No. 4620, 627-634. https:// doi.10. 7901/2169-3358-1995-1-627

Owens, E.H. and Reimer, P.D. (2021). Case Study of a Fuel Oil Spill into a Mountain Stream Successfully Remediated by Mechanical Mixing. Proc. 2021 International Oil Spill Conference. (In press)

Owens, E.H., Reiter, G.A., and Challenger, G. (2000). Stream Remediation following a Gasoline Spill. Proc. $23^{\text {rd }}$ Arctic and Marine Oilspill Programme (AMOP) Technical Seminar, Environment Canada, Ottawa ON, 923-944.

Owens, E.H., Robson, W., and Foget, C.R. (1987). A field evaluation of selected beach-cleaning techniques. Arctic, 40(1), 244-257. https://doi. 10.14430/arctic1818

Owens, E.H. and Santner, R. (2021). Integration of a Shoreline Response Program (SRP) and Shoreline Assessment Surveys into an Incident Management System for Oil Spill Response. Journal of Environmental Management, 279, 111637. https://doi. 10.1016/j.jen vman.2020.1116 37

Owens, E.H. and Sergy, G.A. (1996). Oil on shorelines and shoreline treatment - A state-of-knowledge review. Proc. 19th Arctic and Marine Oil spill Program (AMOP) Technical Seminar, Environment Canada, Ottawa ON, 1105-1116.

Owens, E.H., Taylor, E., Gmur, S., An. C., Danner, G., and Lee, K. (2021b). Shoreline Response Program (SRP) Decision Support Tool based on the Geographic Variability in Attenuation and Weathering of Oil Stranded in Canadian Marine Coastal Environments. Proc. International Oil Spill Conference. (In press)

Owens, E.H., Taylor, E., O'Connell, K., and Smith, C. (2009). Waste Management Guidelines for Remote (Arctic) Regions. Proc. 32 Arctic and Marine Oils pill Program (AMOP) Technical Seminar on Environmental Contamination and Response, Environment Canada, Ottawa ON, 155-166.

Owens E.H., Taylor, E., Sergy, G., Lee, K., An, C.J., and Chen, Z. (2021a). A practical model of the natural attenuation of oil on shorelines. Journal Environmental Informatics Letters. (In press)

Owens, E.H., Teal, A.R., and Haase, P.R. (1991). Berm Relocation During the 1990 Shoreline Cleanup Program following the Exxon Valdez Oil Spill. Proc. $14^{\text {th }}$ Arctic and Marine Oil spill Programme (AMOP) Technical Seminar, Environment Canada, Ottawa ON, 607-630.

POSOW. (2013). Oiled Shoreline Cleanup Manual. REMPEC, Malta, pp 61. https://www.posow.org/documentation/cleanupmanual.pdf

Prince, R.C., Bare, R.E., Garrett, R.M., Grossman, M.J., Haith, C.E., Keim, L.G., Lee, K., Holtom, G.J., Lambert, P., Sergy, G.A., Owens, E.H., and Guénette, C.C. (2003). Bioremediation of Stranded Oil on an Arctic Shoreline. Spill Science and Technology Bulletin, 8(3), 303-312. https://doi.10.1016/S1353-2561(03) 00036-7

SLRoss. (1984). An Engineering Study of Mechanical Shoreline Cleanup Systems for Oil Spills in Canada. Unpublished Report by SLRoss Environmental Research Ltd, Ottawa ON, to The Canadian Offshore Oil Spill Research Assoc., pp 165.

Sergy, G., Blenkinsopp, S., Westlake, D., Foght, J., and McLeay, D. (1993). The Development of Laboratory Methods for Assessing the Efficacy and Toxicity of Oil Spill Bioremediation Agents. Proc. $16^{\text {th }}$ Arctic and Marine Oil Spill Program (AMOP) Technical Seminar. Environment Canada, Ottawa ON, 355-367.

Sergy, G.A., Guénette, C.C., Owens E.H., Prince, R.C., and Lee, K. (2003). In-Situ Treatment of Oiled Sediment Shorelines. Spill Science and Technology Bulletin, 8(3), 237-244. https://doi.10.101 6/S1353-2561(03)00040-9

Taylor, E., Owens, E.H., Belore, R., Buist, I., Norvik, A.B., and Simmons, J.L. (1995). Beach Protection and Cleaning Equipment and Techni- ques for Oil Spill Response, Marine Response Corp., 
Washington DC, MSRC Technical Report Series 95-006, pp 360.

Taylor, E., Owens, E.H., Lee, K., An, C.J., and Chen, Z. (2021). A review of numerical models for oil penetration, retention and attenuation on shorelines. Journal Environmental Informatics Letters. (In press)

Taylor, E., Owens, E.H., and Norvik, A.B. (1994). A review of mechanical beach-cleaning machines. Proc. 17th Arctic and Marine Oilspill Programme (AMOP) Technical Seminar, Environment Canada, Ottawa ON, 621-634.

Venosa, A.D., Suidan, M.T, Strohmeier, K.L., Haines, J.R., Eberhart, B.L., King, D., and Holder E. (1996). Bioremediation of an Experimental Oil Spill on the Shoreline of Delaware Bay. Environmental Science and Technology, 30 (5), 1764-1775. https://doi.10.1021/ es950754r

Vogel, T.M., and Walter, M.V. (2001). Bioaugmentation. In: Hurst, C.J., Crawford, R.L., Garland, J.L., Lipson, D.A., and Mills, A.L. (eds.) Manual of Environmental Microbiology, American Society for
Microbiology Press, Washington DC, 952-959.

Walker, A.H., Kucklick, J.H, Michel, J., Scholz, D.K., and Reilly, T. (1995). Chemical treating agents: Response Niches and Research and Development Needs. Proc. International Oil Spill Confence, American Petroleum Institute, Washington DC, Publication No. 4620, 211-217. https://doi.10.7901/2169-3358-1995-1-211

Yavari, S., Malakahmad, A., and Sapari, N.B. (2015). A review on Phytoremediation of Crude Oil Spills. Water, Air, and Soil Pollution, 226(8): 1-18. https://doi.org/ 10.1007/s11270-015-2550-z

Zhao, L., Boufadel, M.C., Geng, X., Lee, K., King, T., Robinson, B., and Fitzpatrick, F. (2016). A-DROP: A predictive model for the formation of oil particles aggregates (OPAs). Marine Pollution Bulletin, 106 (1-2), 245-259. https://doi.org/10.1016/j.marpolbul. 2016.02.057

Zhu, X., Venosa, A.D., Suidan, M.T., and Lee, K. (2001). Guidelines for the Remediation of Marine Shorelines and Freshwater Wetlands. U.S. Environmental Protection Agency, Cincinnati OH, pp 156. 
Attachment A. Summary of Operational Considerations for Shoreline Treatment Options

\begin{tabular}{|c|c|c|c|c|}
\hline Method and Rationale & $\begin{array}{l}\text { Potential Environmental } \\
\text { Consequences }\end{array}$ & $\begin{array}{l}\text { Logistics Support and } \\
\text { Labour }\end{array}$ & $\begin{array}{l}\text { Time to Treatment } \\
\text { Completion }\end{array}$ & Waste Generation \\
\hline \multicolumn{5}{|l|}{ Physical Removal } \\
\hline $\begin{array}{l}\text { Manual/Mechanical Removal } \\
\text { - Objective is to } \\
\text { physically remove the } \\
\text { oil. } \\
\text { - Manual methods: } \\
\text { shovels, rakes, sieves, } \\
\text { sorbents and/or vacuums } \\
\text { - Mechanical methods: } \\
\text { earth-moving equipment; } \\
\text { vacuum trucks } \\
\text { Residual amounts of oil } \\
\text { may be left for natural } \\
\text { attenuation or } \\
\text { bioremediation }\end{array}$ & $\begin{array}{l}\text { Removed sediment } \\
\text { may not be } \\
\text { naturally or only } \\
\text { slowly replaced. } \\
\text { - } \quad \text { Temporary beach } \\
\text { habitat disturbance. } \\
\text { - } \quad \text { Potentially } \\
\text { problematic (in } \\
\text { terms of effort and } \\
\text { logistics), especially } \\
\text { in remote or } \\
\text { inaccessible areas, if } \\
\text { manual removal } \\
\text { involves a large } \\
\text { labor force. }\end{array}$ & $\begin{array}{l}\text { - Manual methods } \\
\text { are very labor } \\
\text { intensive. } \\
\text { - Mechanical } \\
\text { methods do not } \\
\text { require a high level } \\
\text { of logistics support } \\
\text { compared to } \\
\text { manual methods }\end{array}$ & $\begin{array}{l}\text { - Manual removal } \\
\text { methods are typically } \\
\text { relatively slow to } \\
\text { undertake and } \\
\text { complete. } \\
\text { - Mechanical removal } \\
\text { methods are } \\
\text { operationally quick. }\end{array}$ & $\begin{array}{l}\text { - Waste generation } \\
\text { may be high and } \\
\text { disposal may } \\
\text { include landfill, } \\
\text { incineration, or } \\
\text { recycling. } \\
\text { - Mechanical } \\
\text { removal may } \\
\text { generate large } \\
\text { volumes of solid } \\
\text { waste. }\end{array}$ \\
\hline $\begin{array}{l}\text { Flooding, Flushing and } \\
\text { Washing } \\
\text { - Objective is to } \\
\text { physically remove the oil } \\
\text { from the shore zone by } \\
\text { flooding, flushing and/or } \\
\text { washing from the shore } \\
\text { zone to the adjacent } \\
\text { waters. } \\
\text { - Manual washing } \\
\text { methods: small pumps, } \\
\text { hoses, collection booms } \\
\text { and recovery equipment } \\
\text { (skimmers or sorbents) } \\
\text { - Mechanical washing } \\
\text { methods: boat- or barge- } \\
\text { based pumping systems } \\
\text { with collection booms } \\
\text { and recovery equipment } \\
\text { (skimmers or sorbents) }\end{array}$ & $\begin{array}{l}\text { Accelerates } \\
\text { evaporation of light } \\
\text { fractions. } \\
\text { Can generate } \\
\text { macroscopic oil } \\
\text { residue-sediment } \\
\text { agglomerates which } \\
\text { may sink if formed } \\
\text { with sediments } \\
>1 \mathrm{~mm} \text {. } \\
\text { - } \\
\text { On coarse-sediment } \\
\text { beaches, the water } \\
\text { may transport oil } \\
\text { into the subsurface. } \\
\text { Field tests typically } \\
\text { are used to evaluate } \\
\text { the effects on flora } \\
\text { and fauna and the } \\
\text { net environmental } \\
\text { benefit. }\end{array}$ & $\begin{array}{l}\text { - Manual methods } \\
\text { are very labor } \\
\text { intensive. } \\
\text { - Mechanical } \\
\text { methods are } \\
\text { operationally } \\
\text { straight forward } \\
\text { and do not require } \\
\text { a high level of } \\
\text { logistics support } \\
\text { compared to } \\
\text { manual methods. }\end{array}$ & $\begin{array}{l}\text { - Manual washing } \\
\text { methods are typically } \\
\text { relatively slow to } \\
\text { undertake and } \\
\text { complete. } \\
\text { - Mechanical washing } \\
\text { methods are } \\
\text { operationally quick. }\end{array}$ & $\begin{array}{l}\text { Typically little or } \\
\text { no oil recovered } \\
\text { from the water } \\
\text { surface except for } \\
\text { medium and } \\
\text { heavy oils and } \\
\text { where shoreline } \\
\text { oil loadings are } \\
\text { high. } \\
\text { - If recovery is } \\
\text { included may } \\
\text { generate high } \\
\text { volumes of } \\
\text { liquids to } \\
\text { manage. } \\
\text { Otherwise, } \\
\text { primarily } \\
\text { operational } \\
\text { support wastes. }\end{array}$ \\
\hline \multicolumn{5}{|l|}{ Physical In-Situ Treatment } \\
\hline $\begin{array}{l}\text { Manual/Mechanical Sediment } \\
\text { Dry Mixing } \\
\text { - Objective is to } \\
\text { physically disturb the } \\
\text { oiled layers to increase } \\
\text { the surface area and } \\
\text { exposure greater oil } \\
\text { volumes to physical and } \\
\text { biological weathering } \\
\text { processes without } \\
\text { oil/sediment removal. }\end{array}$ & $\begin{array}{l}\text { - No loss of sediment; } \\
\text { sediment } \\
\text { redistribution by } \\
\text { wave action } \\
\text { typically restores } \\
\text { the beach form and } \\
\text { hydrology in one or } \\
\text { two tide cycles. } \\
\text { Temporary beach } \\
\text { sediment and } \\
\text { habitat disturbance. }\end{array}$ & $\begin{array}{l}\text { - Manual methods } \\
\text { are very labor } \\
\text { intensive. } \\
\text { - Mechanical } \\
\text { methods do not } \\
\text { require a high level } \\
\text { of logistics support } \\
\text { compared to } \\
\text { manual methods. }\end{array}$ & $\begin{array}{l}\text { - Manual removal } \\
\text { methods are typically } \\
\text { relatively slow to } \\
\text { undertake and } \\
\text { complete. } \\
\text { - Mechanical removal } \\
\text { methods are } \\
\text { operationally quick. }\end{array}$ & $\begin{array}{l}\text { - Only operational } \\
\text { support waste is } \\
\text { generated. }\end{array}$ \\
\hline $\begin{array}{l}\text { Manual/Mechanical Sediment } \\
\text { Wet Mixing } \\
\text { - Objective is to disturb } \\
\text { the oiled layer while it is } \\
\text { covered by water to } \\
\text { increase the surface area } \\
\text { and exposure greater } \\
\text { volumes to physical and } \\
\text { biological weathering } \\
\text { processes without } \\
\text { oil/sediment removal. }\end{array}$ & $\begin{array}{l}\text { No loss of sediment; } \\
\text { sediment } \\
\text { redistribution by } \\
\text { wave action } \\
\text { typically restores } \\
\text { the beach form and } \\
\text { hydrology in one or } \\
\text { two tidal cycles. } \\
\text { Temporary beach } \\
\text { sediment and } \\
\text { habitat disturbance. }\end{array}$ & $\begin{array}{l}\text { - Manual methods } \\
\text { are very labor } \\
\text { intensive. } \\
\text { - Mechanical } \\
\text { methods do not } \\
\text { require a high level } \\
\text { of logistics support } \\
\text { compared to } \\
\text { manual methods. }\end{array}$ & $\begin{array}{l}\text { - Manual removal } \\
\text { methods are typically } \\
\text { relatively slow to } \\
\text { undertake and } \\
\text { complete. } \\
\text { - Mechanical removal } \\
\text { methods are } \\
\text { operationally quick. }\end{array}$ & $\begin{array}{l}\text { Only operational } \\
\text { support waste is } \\
\text { generated. }\end{array}$ \\
\hline
\end{tabular}




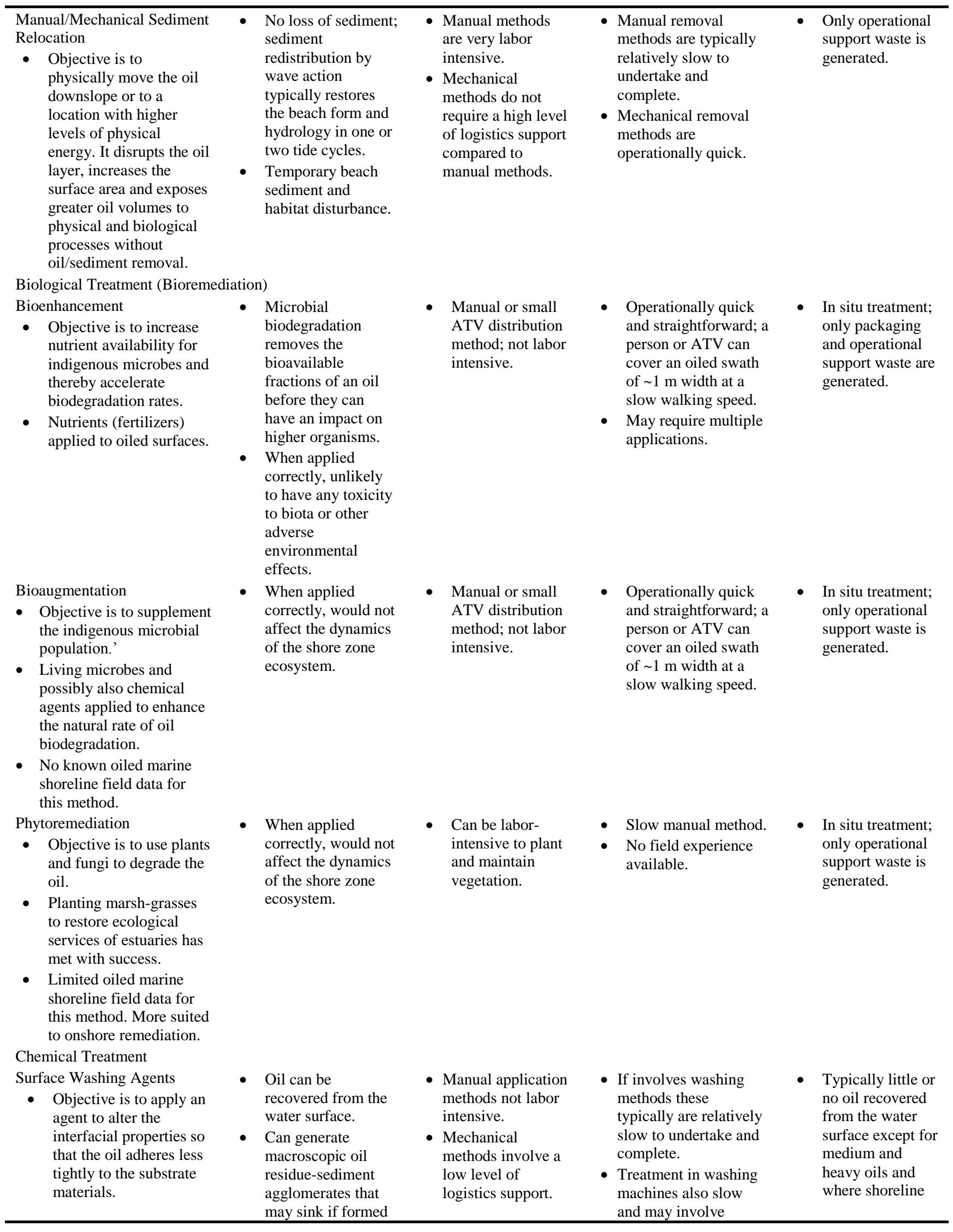


- Oil is then remobilized by a rising tide or physically washed from the shore.

- Oiled sediments may be treated in a purposebuilt washing unit that contains the agent.

Stabilization or Coating

Dispersant Agents

- Objective is to apply an agent to disperse stranded oil.

- Creates small oil droplets which have a high surface area to volume ratio to accelerate biodegradation.

Thermal Treatment

Burning

- Objective is to eliminate oil in vegetated grassy shore types (marshes) or on combustible debris (e.g. logs, branches).

Incineration

- Objective is to eliminate oil mixed with sediment by combustion in purposebuilt equipment. with sediments

$>1 \mathrm{~mm}$.

- On coarse-sediment

beaches, the

treatment may

transport oil into the

subsurface.

- Smothering effect of oil on intertidal organisms

- Oil disperses into the water column as small droplets or particles.

- Oil is nonrecoverable.

- When applied correctly, unlikely to have toxicity to biota or other adverse environmental effects.

- Burning in an oiled wetland or marsh

follow wellestablished guidelines to avoid undesirable consequences.

- Localized, temporary smoke generation.

- Methods follow well-established industry standards and practices.

- Typically, oiled materials are removed mechanically or manually and transferred to the incineration unit.

- Temporary beach habitat disturbance.

multiple transfers, which are best handled mechanically for efficiency.

oil loadings are high.

- Primarily operational support waste.

- Manually inject binders into the oiled zone or exsitu.

- Mechanical methods involve a low level of logistics support.

- Manual application methods not labor intensive

- Mechanical methods involve a low level of logistics support.
- Depend on the beach type and equipment used

- Dispersion is rapid (minutes to hours) depending on water exchange rates at the shoreline.
- In situ treatment; only operational support waste is generated.
- Marsh burning would not require much support.

- Manual methods of debris transfer likely very labor intensive.

- Mechanical debris transfers would not require a high level of logistics support.

- Manual methods of transfer and operation very labor intensive.

- Mechanical transfer to an off-site or nearby location; would not require a high level of logistics support.
- Rapid time to completion for marsh grass and debris burning.

- Slow, depending on actual equipment used.

- May involve multiple transfers.
- In-situ treatment; only operational support waste is generated.
- In situ or nearby treatment.

- Would generate cleaned sediments for transfer back to site as well as operational support waste. 